\title{
DERECHO AL OLVIDO
}

\section{Carlos Hermoza Horna}

¿Y si escribo tu nombre en el navegador de internet con la finalidad de saber algo de ti, quien eres y que haces, o viceversa? Dicen que en internet se puede encontrar todo y de todo sobre todo el mundo, valga la redundancia. ¿Será cierto esto? Suena tentador poder tener al alcance de tus manos tanta información y que con una simple búsqueda en esta famosa red, se pueda llegar a tener todo el perfil de una persona sin necesidad de conocerla. ¿Prejuicios? ¿Falsas impresiones? ¿Noticias falsas o verdaderas? ¿Asesinos, violadores, rateros, etc., lo seguirán siendo? ¿Es que acaso es tan fácil poder llegar a conocer a alguien leyendo lo que algunas personas, admiradores, amigos, enemigos de esta, escriban? ¿Qué limites hay para toda esta cuestión? ¿Cómo se sentirá uno si es que escriben cosas que lo desprestigian en un lugar tan público y de fácil acceso como lo es el internet? ¿Existirá algún freno para todo esto?

Estas son solo algunas de las tantas preguntas que no solo yo, sino la mayoría de personas se hace al sentarse frente a un ordenador y "googlear" a otra de su interés.

Qué hacer ante esta terrible situación, en la que leer algo sobre alguien implica develar sus más intimas misterios y secretos; despertar el pasado y traerlo al presente, con un único objetivo, el desprestigio y la afectación a la honorabilidad o no de una persona.

Que hacemos cuando a una persona se le juzga o multa en un determinado momento, generándose asi una determinada información asociada a este hecho, que según [a repercusión social que haya tenido en ese entonces, pueda ser publicada en diferentes medios de comunicación, generándole asi un grave problema: el atamiento de estos datos o informaciones al nombre de la persona implicada a lo largo de su vida, persiguiéndola como una especie de sombra que aparece cuantas veces se realice una simple búsqueda de su nombre en internet. 
El salvavidas a esta situación es el denominado Derecho al olvido "', para evitar así este tipo de situaciones. ¿Existirán mecanismos para poder borrar datos personales de internet? ¿La constitución verdaderamente nos protege de inescrupulosos que afectan nuestros tan elementales derechos?

Desde mi punto de vista, efectivamente la constitución nos ampara frente a todo tipo de actos que vulneren nuestros derechos, que nos causen algún agravio como persona o algún prejuicio.

El problema está en que muchas veces las personas no hacen respetar sus derechos por la falta de conocimiento de los mismos, o por paradigmas sociales como el "qué dirán". Muchas veces se prefiere evitar el escándalo a simplemente interponer una demanda para defender nuestros derechos como personas. Como bien dice el dicho "Dios perdona el pecado, pero no el escándalo".

En una sociedad tan llena de malas costumbres como la nuestra en la que el chisme es lo que más vende, publicar temas personales e intimas es lo que más llama la atención, entre otras demás actividades que vemos todos los dias en programas locales, no son más que una muestra que no hay un respeto hacia los demás. Dicen que tus derechos acaban cuando empiezan los del otro. ¿ Se cumple realmente esto? O es que estamos acostumbrados sencillamente a pasar por encima de todos, publicar, destapar, hacer "ampays" como se llama hoy en dia, con el único de afán de tener algo más de audiencia.

¿Qué datos tienen derecho a recabar de mi? ¿De qué manera? ¿Con qué finalidad? ¿Por cuánto tiempo pueden ser accesibles al público?

Preguntas con innumerables respuestas, con un sinfin de normas y leyes que respalden el acceso a nuestras informaciones. Y si hay tanta seguridad jurídica, ipor qué hay tantas demandas ${ }^{(2)}$ contra portales de internet, programas televisivos, entidades privadas y públicas, etc.? Sencillamente porque en una era tan materialista como la nuestra, se prefiere vender a costa de la información ajena, a cumplir con lo que manda la ley. Y si se cumple, no se cumple de una manera adecuada. Y si se cumple de una manera "adecuada", siempre habrá una forma de justificar la irregularidad. Como dice el dicho "Hecha la ley, hecha la trampa".

(1) Delgado Antonio. Fundación Eroski consumer. "El derecho al olvido: borrar los datos personales en internet". 2. de mayo de 2011:/http:/www_consumer.es/web/ es/tecn ologiafintemet/2011fOS/02/Z00189.php

(2) 2.-Garcia Carolina. "las reclamaciones sobre el 'derecho al olvido en Internet' aumentan un $56 \%$ en 2010".Sociedad.EI Pais.com. (http://www.elpals.com(an:iculojsociedad/reclamacicnes/derech\%lvido/Intemet/aumentan/56/201O!elpepusocj:20110524elpepusoc_ $7 /$ Tes 
Hagamos el intento y sentémonos en un ordenador, abramos internet, y "googlemos" a la persona que venga rápidamente a nuestra mente. Por ejemplo al ex presidente Alan García. Escribimos rápidamente su nombre en el buscador y así como nos aparecen tantas paginas que hacen honor a su anterior gobierno, salen otras que dicen lo siguiente:" Alan nunca mas... No más- Todo sobre el desastroso gobierno de AGP que no debe repetirse jamás"(3).

El ejemplo anterior, es de una web creada hace más de diez años, la cual no hace más que recordar las épocas de crisis del primer gobierno Aprista, que desprestigia totalmente al ex presidente y que fue creada con el único afán de mantener viva la memoria de la gente por medía de tantos malos recuerdos.

¿Será justo esto? Han pasado más de veinte años y aun así hay personas que se dan el lujo de crear sombras que persigan a tantas personas. ¿Qué pasaría alguien que no tiene la más mínima idea de quién es o ha sido el ex presidente Alan Garcia? Así como leería cosas buenas de él, se tomaría con el sin fin de paginas que lo desprestigian totalmente y no lo dejan vivir en paz.

En la otra esquina del ring, nos encontramos con el actual presidente, Ollanta Humala. Al escribir su nombre en la web, nos sale como primera página un portal enciclopédico con un prestigio mundial, Wikipedia ${ }^{(4)}$. Esta página nos presenta una hermosa biografía del actual presidente, pero como era de esperarse y para los amantes del pasado de la gente, infaltable era lo siguiente: "Durante la campaña política electoral de 2006, en la que Humala postulaba a la presidencia del Perú, fue acusado por la ejecución y desaparición de población civil en la zona roja, estos crímenes se habrian cometido durante los años 90 mientras Humala prestaba servicios en Huánuco con el seudónimo de «capitán Carlos». Según esta denuncia, presuntamente en 1992, en la base militar de "Madre mía» (Pucayacu), se cometieron una serie de abusos contra la población civil, razón por la cual fue investigado por el Poder Judicial. En el año 2009 , el caso fue cerrado por falta de pruebas".

Siguiendo con la misma página web $^{(5)}$, líneas más abajo: «En media de la campaña presidencial del 2011 , en la que Humala postulaba nuevamente a la presidencia del Perú, el caso de Madre Mía volvió a los medios de comunicación ${ }^{(6)}$.

\footnotetext{
(3) Asociación Juvenil"Alan Nunca más... No más". Mayo 31,2001. http://alangarcia.itgo.com/

(4) Ollanta Humala. http://es.wiklpedia.org/wiki/Ollanta_Humala

(5) (CRONOLOGIA) 'Andahuayl,Ilo', el intento de golpe que dejó seis rnuerrOS>1. El Comercio. 2.4.05.2011

(6) Poder Judicial archivo proceso contra Humala por caso "Madre Mia". www.Perủ.com
} 
Como nos podemos dar cuenta, hechos de hace más de veinte años, al igual que en el caso del ex presidente García, siguen reviviendo cada vez que se busca información sobre alguien. ¿Es que acaso no hay un dẻrecho al olvido y una segunda oportunidad de hacer las cosas mejor? ¿Por qué tanto afán en hacer daño a las personas a costa de su pasado?

Sigamos con nuestra búsqueda en la Web. Googlearemos esta vez no a un político, sino a un personaje $\mathrm{X}$ de la farándula limeña que cuando también escuchemos su nombre lo primero que salte a la mente sea algo de su pasado. Se me ocurre googlear a la señorita Malú $\operatorname{Costa}^{(7)}$, y oh sorpresa lo primero que leo en la web es que es una reconocida modelo del mundo de los espectáculos, que hoy en día le va muy bien, es una persona exitosa y más abajo siguiendo con mi lectura, me topo con otro montón de páginas que recuerdan su "ampay “ con un futbolista en el que se muestra un acto bastante «intimo" por asi denominarlo y también sus anteriores problemas con la justicia. En conclusión la señorita pasó de ser una modelo reconocida, a una chica con amplias malas costumbres y problemas con la justicia. ¿Cómo cambio el concepto que teníamos de ella en un abrir y cerrar de ojos, no? y todo por publicaciones pasadas que siguen circulando por la Web.

Para terminar, para hacer hincapié en que este problema no es solo peruano, sino mundial, hagamos de cuenta que no conocemos a la reconocida cantante "Britney Spears"(8). Siguiendo con el mismo procedimiento, buscaremos información sobre quién es ella. Evidentemente entre las noticias más recientes, hay un sin número de portales que muestran su reciente gira, el lanzamiento da su reciente disco, lo buena madre que es con sus hijos y las obras de caridad que viene realizando en la actualidad. Aparentemente no solo es una profesional intachable, sino una buena madre.

Sin embargo, en otras páginas web, para los amantes del NO olvido, se publican todos sus problemas en el pasado, tales como su estadía en prisión, su matrimonio en Las Vegas, el cual duró solo 55 horas, que a sus 26 años el estado le dio la tutoría de ella misma a su padre, producto del sin fin de problemas por el que cursaba, las peleas con los paparazzi, problemas con el alcohol, drogas, dinero y para terminar la perdida de tenencia de su hijo de cinco meses, producto que lo llevaba al volante a su corta edad, atentando contra su vida.

(7) Malu Costa. http://www.google.com.pe/

(8) Britney Sped fS. Problemas persona les. http://es.wikipedia.org/wlkijBritney-Spears\#Prob lemas persona les 
¿Es que acaso hay derecho a reinsertarse en la sociedad y hacer las cosas mejor? ${ }^{\text {(9) }}$

Pongamos el siguiente caso hipotético y más al alcance de nuestra realidad social. Es el caso de una persona que tras haber cumplido su condena en la cárcel, producto de sus problemas con la justicia, más específicamente violación a un menor de edad o cambiando el delito, hurto agravado, sale a las calles con la mejore de las intenciones y es así que comienza a buscar trabajo para reivindicar su vida. Supongamos que se acerca a un centro de estudios en busca de trabajo en cualquier puesto. El director, al ver sus antecedentes penales automáticamente considera que una persona que ha violado o ha robado no puede trabajar en su centro de estudios, y le pide por favor se retire. Y es así que ocurre lo mismo en las diferentes ocasiones que esta persona se presenta a una entrevista de trabajo. La sombra de su pasado y la información que lleva consigo no le permiten llevar una vida digna, ya que en nuestra sociedad el derecho a olvido no existe para muchos.

La Constitución Política del Perú(10) ampara nuestros derechos pero con ciertas limitaciones. Lamentablemente esa función resocializadora que protege nuestra constitución no se cumple, debido a los paradigmas de nuestra sociedad: " El que lo hizo una vez, lo puede volver a hacer otra vez".

Si bien es cierto que una vez cumplida la condena, nada asegura que el sujeto vuelva a cometer los mismos actos, creo yo, debería existir una segunda oportunidad para el mismo. De ser el caso que exista la reincidencia del mismo, estoy completamente de acuerdo que se le aplique todo el peso de la ley.

El individuo procesado y sancionado, una vez cumplida su pena, debería poder reintegrarse a la sociedad y aprovechar así la segunda oportunidad que se le brinda.

La existencia de datos al alcance de la ciudadanía considero es un arma de doble filo, ya que si bien nos sirve para poder apreciar datos especificas de nosotros

(9) Título Preliminar del Código Penal Articulo IX.- Fines de la Pena y Medidas de Seguridad La pena tiene función preventiva, protectora y resocializadora. Las medidas de seguridad persiguen fines de curación, tutela y rehabilitación.

(10) Constitución Politica del Perú. Art 2".N2 4. Toda persona tiene derecho a las libertades de Información, opinión, expresión y difusión del pensamiento mediante la palabra oral o escrita o la imagen, por cualquier medio de comunicación social, sin previa autorización ni censura ni impedimento algunos, bajo las responsabilidades de ley.

$N^{0} 5$. A solicitar sin expresión de causa la información que requiera ya recibirla de cualquier entidad pública, en el plazo legal. con el costo que suponga el pedido. Se exceptuan las información es que afectan la Intimidad personal y las que expresamente se excluyan por ley o por razones de seguridad nacional. 
mismos, brindarnos seguridad y credibilidad respecto a lo que es cada uno, para poder así saber con quién o quiénes estamos tratando, deben ser usados diligentemente y dentro de los parámetros del derecho.

Si bien cada uno de nosotros puede pedir información con respecto a la esfera más intima de las demás personas, estos requerimientos deben hacerse dentro de los márgenes de la ley y con respeto a los derechos fundamentales de cada personas, los cuales que son la base de toda sociedad que vive en un estado constitucional de derecho.

El derecho al olvido debe ser manejado de la mejor manera y acorde a las vigentes normativas que lo reconocen, ya que la publicación de datos personales en Internet debe ir de la mano con la posibilidad de solicitar la supresión de los tales datos, logrando así estos no vuelvan a parecer en buscadores tan comúnmente usados como es el Google o redes sociales tan amplias como 'es el reciente boom informático del Facebook (11).

El derecho al acceso de la información pública debe ir de la mano con la protección de los derechos humanos. Definitivamente la información resulta ser valiosa para el ciudadano en su vida diaria, pero cuando esta no se usa diligentemente, puede ser perjudicial para él mismo.

La Ley $29733^{(12)}$, en su artículo 13, nos brinda una amplia visión de lo que es el derecho de acceso a la información, que en resumidas cuentas nos dice lo siguiente:

- El tratamiento de datos personales deberá realizarse con pleno respeto de los derechos fundamentales de sus titulares, garantizándose principalmente el derecho fundamental a la protección de los datos personales previsto en la Constitución Politica del Perú, en un marco de los demás derechos fundamentales que en ella se reconocen. Asimismo, el Código Procesal Constitucional $^{(13)}$ reconoce en su articulo 61, la figura del Habeas Data, el cual es un mecanismo de defensa de los derechos constitucionales reconocidos en los incisos 5 y 6 del articulo 2 de la Constitución.

Las personas podrán hacer uso de este mecanismo para:

(11) Las Redes Sociales deberán garantizar el "derecho al olvido“ Tecnologia e Información” Seguridad Informática. http://www.articulo.tv/?las-redes-sociales-deberan-garantilarderecho-al-olvido. 1942

(12) Ley 2.9733. Articulo 13.

(13) Código Procesal Constitucional. Articulo 61 
1) Acceder a información que obre en poder de cualquier entidad pública, ya se trate de la que generen, produzcan, procesen o posean, incluida la que obra en expedientes terminados o en trámite, estudios, dictámenes, opiniones, datos estadísticos, informes técnicos y cualquier otro documento que la administración pública tenga en su poder, cualquiera que sea la forma de expresión, ya sea gráfica, sonora, visual, electromagnética o que obre en cualquier otro tipo de soporte material.

2) Conocer, actualizar, incluir y suprimir o rectificar la información o datos referidos a su persona que se encuentren almacenados o registrados en forma manual, mecánica o informática, en archivos, bancos de datos o registros de entidades públicas o de instituciones privadas que brinden servicio o acceso a terceros. Asimismo, a hacer suprimir o impedir que se suministren datos o informaciones de carácter sensible o privado que afecten derechos constitucionales.

Finalmente existen tipos de habeas data, mediantes los cuales se puede solicitar, corregir, asegurar, excluir, garantizar, actualizar, agregar y limitar todo tipo de datos al bance de informaciones, logrando asi se haga un uso diligente de los mismos y se protejan los derechos fundamentales de las personas.

Es el caso de los dos tipos de habeas data existente y sus subtipos respectivos:

- Habeas data Informativo (Localizador, finalista, exhibitorio, autoral).

- Habeas data Reparador (Aditivo, rectificador, cancelatorio, reservador, asegurador, encriptador y bloqueador). 